\title{
Research Involving Human Subjects and the Role of Institutional Review Boards in Brazil
}

\author{
Carla A. Arena Ventura ${ }^{1}$, Isabel Amélia Costa Mendes $^{2}$, Maria Auxiliadora Trevizan ${ }^{1}$, \& Leila Maria Marchi-Alves ${ }^{3}$ \\ ${ }^{1}$ Full Professor, University of São Paulo at Ribeirão Preto College of Nursing, Brazil. \\ ${ }^{2}$ Associate Professor, University of São Paulo at Ribeirão Preto College of Nursing, Brazil. \\ ${ }^{3}$ Professor, University of São Paulo at Ribeirão Preto College of Nursing, Brazil. \\ Correspondence: Isabel Amélia Costa Mendes. RN, Ph.D. in Nursing, University of São Paulo at Ribeirão Preto College \\ of Nursing, Brazil.
}

Received: February 11, 2015

Accepted: February 27, 2015

Available online: March 13, 2015

doi:10.11114/ijsss.v3i3.717

URL: http://dx.doi.org/10.11114/ijsss.v3i3.717

\begin{abstract}
Background, the regulation of research involving human subjects through the creation of Institutional Review Boards (IRBs) aims to consolidate a culture of respect for human rights, mainly of research subjects.

Method, This study discusses the regulations for the development of research involving human subjects and the role of IRBs in Brazil.

Results, More than half of the IRBs are located in the South and Southeast, where IRBs are being consolidated. Progress is being made in Brazil as a result of Resolutions 196/96 and 466/12, however, challenges continue. In response to deficits in researchers' and research institutions' appreciation of, and lack of commitment to, ethical research practice IRBs have an important educative role. IRBs need to make their work transparent for the entire community and demonstrate the ability to enhance the organizational climate of institutions.

Conclusions, Some deficits exist in the scientific community's understanding of the importance and role of IRBs, as well as in the excessive bureaucratization of the relationship between researchers and IRB members. In a country with so many regional differences, despite national regulations, IRB members should recognize and effectively deal with local particularities to guarantee respect for research subjects' dignity.
\end{abstract}

Keywords: Research, Ethics, Institutional Review Boards, Policy

\section{Background}

Regulations for scientific research involving human subjects have been developed in countless countries in recent decades. This movement started in Europe and the USA after the Second World War and then spread to other regions, mainly resulting from international research cooperation.

Consequently, minimal standards were formulated for the protection of human beings serving as research subjects, including the creation of Institutional Review Boards (IRBs). Thus, international rules and guidelines established that any research proposal involving human subjects should be submitted to one or more ethical and scientific Institutional Review Boards to consider its scientific merit and ethical acceptability. These boards should be independent from research teams and should not gain any financial or material benefit from the research process.

In this direction, there is an international movement to increase the legal and regulatory control of research involving human beings and four models of IRB regulation can be found (Barbosa \& Boery, 2010): a) model based on legislation or detailed regulation, which establishes a regulatory structure for the IRBs, as in France and Denmark; b) the establishment of formal legal responsibility requisites, leaving research institutions in charge of developing their own ethical review systems, maintaining centralized support mechanisms, as in the USA; c) a model in which governmental entities, often scientific research funding agencies, adopt guidelines or recommendations for research protocols with governmental funding, as in Canada, South Africa and Australia and d) the adoption of a legal structure that integrates international guidelines into existing national standards, as in the European Union through the establishment of the EU Directive on Clinical Trials in 1997. In spite of this classification, one may find elements of a model within the 
organization of the others, such as the integration of international guidelines into national regulatory systems. Considering the importance of the protective function of the IRBs, these boards' legitimacy constitutes a primary concern in the sphere of different possible models (Tannahill \& Douglas, 2014; Freitas \& Novaes, 2010).

With respect to Brazil, considered a civil law system, there are particular aspects of legislation, including detailed rules that approximate it to the first model. Brazilian laws focus on legislation aiming at covering all studies involving human subjects (Freitas \& Novaes, 2010).

Therefore, in view of the risks inherent in healthcare research which may diminish an individuals' physical, psychological and social well-being, the Brazilian National Health Council Resolution 196/96 created the National Research Ethics Committee. This entity coordinates the administrative process of the research monitoring system in the country, especially through the establishment of Institutional Review Boards.

Through this perspective, IRBs represent an important tool to safeguard the rights of research participants and researchers. Emphasizing their relevance, this paper aims at presenting the scenario for the implementation of IRBs in Brazil.

\subsection{Rules for Research Involving Human Subjects around the World and the Role of Irbs: Advances and Challenges}

After the Second World War, in 1947, the first regulatory standards for research involving human subjects were set, which were necessary especially due to the abuses experienced during war conflicts (Sarlet, 2009). Since then, the scientific community has been based on the premise that human subjects' voluntary consent is absolutely essential and that people who will be submitted to any experiment should be legally capable of consenting, exercising the free right to choose without any external intervention and aware of the study object (Diniz, Sugai, Guilhem, \& Squinca, 2008). Also, despite these initial efforts, research experiences were still reported as characterized by great ethical distortions, such as the Tuskegee project, a clinical study conducted between 1932 and 1972 by the Unites States Public Health Service, involving 600 black men with the goal to record the natural history of syphilis. The study was developed without the benefit of patients' informed consent and framed future discussions on research ethical standards. In view of this scenario, rules for research involving human subjects became part of public policies and social practices in different countries, especially developed nations, with a view to broadening and guaranteeing citizens' rights. It is also highlighted that transformations in scientific and technological practice also drove this movement, influencing health services' daily routine (Freitas \& Novaes, 2010).

As a consequence of this scientific research regulation process, submitting research projects to IRBs, responsible for assessing the studies based on ethical principles, became compulsory. Researchers intending to publish their work in international journals mandatorily need IRB approval. Moreover, in case of multicenter projects that involve researchers from different institutions, approval from more than one IRB is required (Jacobsen, 2011; Gold \& Dewa, 2005).

Thus, one may affirm that lessons were learned from the evolution of research involving human subjects. Nevertheless, although more than 50 years have passed since the Nuremberg Trials and the Nuremberg Principles, there are still studies conducted unethically even in and by developed countries (Keeland, 2008), such as the Wakefield study in 1998 or the approximately 86 articles led by a renowned clinical researcher at the Klinikum Ludwigshafen, Germany, between 1999 and 2009, found not to have had approval from an IRB (Harrell, 2010; Benatar, 2002).

The idea that universal standards exist for the analysis of projects involving human subjects, however, does not take into account the economic, cultural and social diversity that exists around the globe. Although developing countries have to fulfill the same obligations of developing countries, great social exclusion is still observed in health, especially in low-income countries. In this context, Brazil is an upper-middle income country characterized by a level of human development which has grown steadily over the past three decades. However, in spite of these improvements, Brazilian social inequality is historical, and it has been through different periods, various economic models, dictatorships and democratic transitions since its colonial past (Keeland, 2011).

Hence, one of the main challenges rules for research involving human subjects and for IRB activities have to face is exactly the attempt to avoid past errors, as well as new forms of discrimination and victimization in this increasingly complex age of biotechnological evolution (King, Henderson, \& Stein, 1999). In that sense, besides analyzing the project's scientific merit, the IRBs should understand the study's ethical merit (Sawaia, 2005; Debert, 2003; London, 2000). Many doubts exist though, about the effectiveness of increasing research rules and bureaucracy related to research studies and their actual benefits to protect human beings. For many researchers, IRBs have become yet another barrier to be conquered in the development of their work, instead of finding that their activity can represent an important step towards safeguarding the dignity of research participants, as well as a learning possibility for all stakeholders. Also, an increased number of scientific publications are observed in developed countries, where IRBs have been active for some time. In medium and low-income countries, on the other hand, there is a lack of information 
on IRBs' activities, besides an increase in the so-called ethical "bureaucracy", associated with international collaborative studies (Valdez-Martinez, Trumbull, Garduño-Espinosa, \& Porter, 2005; Oguz, 2003).

The challenges mentioned above strengthen the argument that regulation alone is not sufficient. In this context, it should be taken into account that the application of rules in the context of IRBs involve a complex social picture that covers not only the principles and details of regulations, but also characteristics of the culture at the institution the IRB is part of, as well as participants' skills, behaviors, attitudes, perspectives, values and moral commitment (Valdez-Martinez et al., 2005; Gilbert, Fulford, \& Parker, 1989).

In view of advances achieved as a result of international rules for scientific research involving human beings and the challenges to be faced, especially by countries that are still consolidating their rules, this paper focuses on the implementation context of ethical guidelines for research development involving human subjects in Brazil.

\subsection{Ethical Guidelines for Scientific Research Development in Brazil}

Brazil is the largest country in both South America and Latin America regions. It is the world's fifth largest country, both by geographical area and by population, with over 193 million people. Brazil is a federation composed of 26 states, one federal district and municipalities. The country comprises five geographical regions with contrasting economies and social indicators. Population and regional demographic data show that the North is the largest region in territorial terms and that the highest demographic density and population concentration are located in the Southeast, followed by the Northeast. The highest urbanization degree is found in the Southeast, Central-West and South, regions with the highest level of economic dynamics. Regional inequalities are reflected in noteworthy differences among economic growth and human development ratios, which are higher in the Southeast and South (IBGE, 2014).

In Brazil, after the dissemination of the 1988 Federal Constitution, which followed the transition from military to civilian rule and is considered a landmark in the consolidation of fundamental rights in the country, in line with the international movement to protect human rights, the public policy to regulate scientific research is put in practice.

Thus, only in 1988, the National Health Council edited Resolution n. 1/88, addressing ethical issues in research in a very broad sense and presenting significant gaps. Resolution n. 1 standardized some ethical aspects of research review involving human subjects, including research on new prophylactic resources, therapeutic and rehabilitation diagnoses, research involving minors and women, research involving organs, tissues and derived products, pharmacological research, among others. Despite its relevance as a first attempt towards the national standardization of scientific research, however, the acceptance of the 1988 Resolution was inexpressive and its practical application was not often considered by researchers. In 1995, a 15-member group was created to reassess the 1988 resolution. After one year of work, Resolution 196/96 was issued, called Guidelines and Regulatory Standards for Research involving Human Subjects (Marques, 2007; Hossne, 2006).

This resolution was elaborated based on multi and interdisciplinarity, covering suggestions from different social segments and regulating that any research involving human subjects has to be submitted to an IRB. It was based on the 1947 Nuremberg Principles, the 1948 Universal Declaration of Human Rights, 1964 Helsinki Declaration, 1966 UN Covenant on Civil and Political Rights and the 1982 Proposals for International Ethical Guidelines for Biomedical Research involving Human Subjects. The main goal was to specify the duties of the scientific community to safeguard the rights of research subjects (CNS, 1996).

The Brazilian initiative was a pioneer in Latin America, based on the social order defined in the 1988 Brazilian Constitution, and particularly on the community participation concept, which is one of the guidelines of the country public universal health system (SUS). The Institutional Review Boards and the National Research Ethics Committee (CONEP) were proposed to act as ethical-political discussion laboratories for emerging techno-sciences. This would impose social control on scientific practices, scrutinizing them from an ethical viewpoint, with a view to avoiding coercion or exploitation of the most vulnerable people in society. Safeguarding research subjects from exposure to unnecessary risks and foreseeable damage was also an important aim. In that sense, one can affirm that the implantation phase of this policy is being concluded in Brazil (Diniz et al., 2008).

Besides Resolution 196/96, other instruments exist that regulate different aspects of research involving human beings including, entitled, addressing Clinical Pharmacology Research with regard to authorization, monitoring, responsibilities of researchers and sponsors, ethical requisites and need to obtain pre-clinical and clinical information. Resolution 251/97 incorporates Resolution 196/96 and refers to the Common Market Group Resolution, defining new drugs, medications, vaccines or diagnostic tests. Concern with this issue made Brazil, before the October 2000 revision of the Helsinki Declaration; approve National Health Council Resolution 301/00. Soon afterwards, with a view to complementing the Guidelines and Regulatory Standards for Research Involving Human Subjects, the National Health Council approved Resolution 303/00, addressing the human reproduction area. Concerned with the vulnerability of 
Native Americans and their culture as a result of increasing interest in research involving indigenous population, approved Resolution 304/00. As for research coordinated from abroad or with foreign participants, Resolution 292/99 was created to regulate this practice and seek guarantees for the fair distribution of burden and benefit among stakeholders. In 2012, the Resolution 466 was approved and substitute the Resolution 196, detailing even more the ethical aspects which should be considered in the analysis of research projects involving human subjects by IRBs. These resolutions are examples of the model for IRBs adopted in Brazil, based on detailed regulations.

In addition, according to Brazilian legislation, each IRB should comprise at least seven non-remunerated members, including professionals from health, natural, social, human sciences, and at least one lay representative from the service users, gaining a multi and cross-disciplinary nature. The institution chooses half of the members, while the remainder is elected among professionals with research experience, on a three-year mandate. The resolution impedes a corporatist composition, preventing more than half of IRB members coming from a single professional category.

In this context, the National Committee and IRBs are boards with public power that should serve as independent instances of researchers, essentially defending the interests and rights of research subjects. This system is based on a new social order in the country, departing from the constitutional concept of community participation, permitting ethical analysis as a branch of social control organized inside the system coordinated by the National Health Council (Barbosa \& Boery, 2010).

According to Resolution 466/12, research covers any activity aimed at developing or contributing to generalizable knowledge. It occurs in human subjects when they are involved individually or as a group, direct or indirectly, partial or totally (CNS, 2012).

Brazilian rules for research involving human subjects incorporated the bioethical principles of autonomy, non-maleficence, beneficence and justice (Tannahill \& Douglas, 2014). In this context, it is highlighted that the emergence and consolidation of bioethics in Brazil was historically associated with Tom Beauchamp and James Childress' Principles of Biomedical Ethics, which is the most acknowledged approach in Brazil today. Thus, bioethics in Brazil is characterized by the importation of theories from central countries, particularly the USA (Diniz, Guilhem, \& Garrafa, 1999). The resolution aligns the autonomy principle with the fundamental ethical requirement of free and informed consent and protection of vulnerable people. Therefore, it is highlighted that free and informed consent presupposes agreement, without any coercion, after receiving and understanding information about the procedures. Its main goal is the protection of research subjects. The resolution also establishes special care in research involving children, adolescents, patients with mental disorders or other subjects with a substantially reduced ability to consent. In these situations, a supported justification for choosing these groups is required, as well as IRB approval, free and informed consent from legal representatives and information to individuals up to the limits of their ability (CNS, 1996).

The resolution relates the bioethical principle of beneficence with the required commitment to maximum benefit and minimum risk in the research. In this perspective, the presence of risk is inherent in research involving human subjects. Risk can be individual, collective, immediate, late, physical and psychic, among others. According the resolution, risk is acceptable in those cases when the goal of a certain research justifies it, when: it offers a great possibility to understand, prevent or mitigate the problem affecting the subject, if the expected benefit is of great importance or if the benefit is equal to or greater than that of another already established alternative (CNS, 1996).

Resolution 466/12 also associates non-maleficence with the requirement to avoid harm. Thus, in case a non-identified harm or risk emerges in a certain research, which was not determined in the consent term, the study should be interrupted. Likewise, when the superiority of one method over another is verified, the best regime should be offered to all subjects. It is also important to highlight that the researcher and institution are responsible for harm. In this case, subjects are entitled of compensation measures and should receive comprehensive care (CNS, 2012).

The resolution also links the principle of justice with research subject selection requirements, guaranteed equal consideration of interests involved, with a significant advantage for the research subject and minimum burden for vulnerable people.

Therefore, the IRBs and CONEP should exert social control over scientific practices, qualifying them based on ethical principles and attempting to avoid exploitation of the most vulnerable people and subjects' exposure to useless risks and foreseeable damage (Barbosa \& Boery, 2010).

In December 2012, there were 417 IRBS in Brazil included in the online platform created by CONEP, named National System of Information on Ethics in involving Human Beings (SISNEP), distributed across the five regions of the country. Table 1 shows the distribution of IRBs according to the institutions they were linked to and the region they were located. 
Table 1. Distribution of Institutional Review Boards (IRBs) according to the institutions they are linked to and to the regions they are located in Brazil. Brazil, 2014

\begin{tabular}{|c|c|c|c|c|c|c|c|c|c|c|c|c|}
\hline \multirow[b]{2}{*}{$\begin{array}{l}\text { Institutions to which the } \\
\text { IRBs were linked }\end{array}$} & \multicolumn{2}{|c|}{ North } & \multicolumn{2}{|c|}{ Northeast } & \multicolumn{2}{|c|}{ Southeast } & \multicolumn{2}{|c|}{ Central-West } & \multicolumn{2}{|c|}{ South } & \multicolumn{2}{|c|}{ Total } \\
\hline & $\mathrm{n}$ & $\%$ & $\mathrm{n}$ & $\%$ & $\mathrm{n}$ & $\%$ & $\mathrm{n}$ & $\%$ & $\mathrm{n}$ & $\%$ & $\mathrm{n}$ & $\%$ \\
\hline & 04 & & 25 & 30,9 & 73 & 34,4 & 06 & & & & 131 & \\
\hline Health Services & & 13,3 & & & & & & 46,2 & 23 & 28,4 & & 31,4 \\
\hline Universities & 18 & 60,0 & 50 & 61,7 & 117 & 55,2 & 06 & 46,2 & 55 & 67,9 & 246 & 59,0 \\
\hline Other organizations & 08 & 26,7 & 06 & 7,4 & 22 & 10,4 & 01 & 7,7 & 03 & 3,7 & 40 & 9,6 \\
\hline Total & 30 & 7,2 & 81 & 19,4 & 212 & 50,8 & 13 & 3,1 & 81 & 19,4 & 417 & 100 \\
\hline
\end{tabular}

Thus, it is observed that among the IRBs, $131(31.4 \%)$ were related to health services, 246 (59\%) to Universities and 40 $(9.6 \%)$ to other organizations, such as Associations and Foundations.

With respect to their regions, 30 (7.2\%) were from the North, 81 (19.4\%) from the Northeast, $212(50.8 \%)$ from the Southeast, 13 (3.2\%) from the Central-West and $81(19.4 \%)$ from the South of Brazil. In sum, more than half of Brazilian IRBs were located in the Southeast and that nearly $70 \%$ of IRBs were present in the South and Southeast, regions where scientific research development and graduate programs are also concentrated (CAPES, 2014). In addition, it is important to mention that IRBs were created mainly at University levels with a tendency of increase in the implementation of IRBs at health services.

Besides quantitative differences in IRB distribution, studies focusing on Brazilian IRBs report on the difficulties the Boards face to find members with research ethics or bioethical preparation, as well as problems to put in practice user participation and involve users in IRB discussions. Also, communication problems with CONEP are mentioned, and the need for further integration among IRBs, as well as for advances in member training (Diniz et al., 2008; Kipper, Loch, \& Ferrari, 1998).

It should be taken into account that IRBs are being consolidated in Brazil, especially in the Southeast, South and Northeast and that they face the challenges listed in this paper. In the other regions, they are still being created and put into practice (Novaes, Gilhem, \& Lolas, 2008). In this scenario of great disparities within Brazil, collaborative research with participants from different regions can face ethical dilemmas which should be addressed linking research ethics to the promotion of social and economic processes that could begin reversing widening disparities in health in the country. Therefore, it is necessary to understand the diverse frameworks of thinking and the implication of different mid-sets and environments in which research projects may be carried out in Brazil, especially in poor areas (Benatar, 2002). In this perspective, the analysis standards based on the ethical principles of Beauchamp and Childress' are predominant and offer a guide for the approval of single or collaborative research projects by the IRBs in Brazil.

Also, some deficits are observed in the scientific community's understanding of the importance and role of IRBs, and also in the excessive bureaucratization of relations between researchers and IRB members. Studies also suggest that Brazilian IRB members' view qualitative research approach would need a different ethical approach (Ramos, Finkler, Gonçalves, \& Caetano Ramos, 2010; Diniz et al., 2008; Nunes, 2008; Schramm, 2004).

In short, a complex social picture exists, involving the activities and modus operandi of IRBs in Brazil, each of which is inserted in a distinct organizational cultural and has its own characteristics in function of its member group. In this context, regulation acts as an instrument to seek balance in the establishment of projects' ethical analysis and attempting to avoid disrespect for the human rights of scientific research subjects. On the other hand, besides regulation, it is important to invest in broadening the functions of IRBs, aiming at giving special attention to risk/benefit ratios and equity in the distribution of benefits and burdens as well as in implementing the role of IRBs to educate and assist faculty, researchers and the community in understanding and appreciating the ethics of research and in monitoring and auditing research, providing accountability to the public (Benatar, 2002).

In addition, considering the commitments of UN and WHO state members with approved resolutions, it is relevant to favor and stimulate the development of health research, as this was a central recommendation established by the World Health Report 2013: the expectation that member states will adopt systems to favor the development of health research. This recommendation includes the definition of research priorities, human resources capacity building and a discussion on the financial support for the research and its application in health care, as well as the establishment of regulation rules, standards and systems (WHO, 2013).

In this sense we include the discussion about the value of IRBs, and the imperative of stakeholder's contribution for the 
planning and implementation of the tasks recommended by the World Health Report, aiming at improving the perspectives of universal health coverage within the principles of equity, safety and well-being of the population (Hanney \& González-Block, 2013).

\section{Conclusions and Policy Implications}

Based on a history of scientific and knowledge advancement always not always respecting human rights or valuing human beings, treating them as objects in many scientific studies, it is fundamental to seek ethical standards in the development of research, as well as in the relation between researchers and research subjects.

This paper illustrated the progress achieved in Brazil as a result of Resolution 196/96 followed by Resolution 466/12, as well as the challenges experienced to consolidate an analysis of ethical merit that focuses on the protection and dignity of research subjects in the country.

In this perspective, IRBs can play a fundamental educative role in the incremental transformation of research institutions' organizational culture, stimulating reflection on the abuse committed in scientific studies and encouraging discussions with researchers and the community about controversial aspects in research projects.

Thus, to the extent that IRBs increasingly play a decisive role in the strengthening process of research ethics, it is essential for the details of their work to be clear and transparent for the entire community. Also, in a country with so many regional differences, despite national regulations, members need to acknowledge and effectively deal with local specificities and particularities, always aiming to safeguard respect for research subjects' dignity.

\section{References}

Barbosa, A. S., \& Boery, R. N. S. O. (2010). Restrictions and potentialities of the operability of the Ethics Committess in Research (IRB). Revista Latinoamericana de Bioetica, 10(2), 88-99.

Benatar, S. R. (2002). Reflections and recommendations on research ethics in developing countries. Social Science \& Medicine, 54(7), 1131-1141. http://dx.doi.org/10.1016/S0277-9536(01)00327-6

Conselho Nacional de Saúde - CNS (1996). Ministério da Saúde (Br): Resolução no 196, de 10 de outubro de 1996. Retrieved from http://www.datasus.gov.br/conselho/resol96/RES19696.htm

Conselho Nacional de Saúde - CNS (2012). Resolução n ${ }^{0}$ 466, de 12 de dezembro de 2012. Retrieved from http://conselho.saude.gov.br/resolucoes/2012/Reso466.pdf

Coordenação de Aperfeiçoamento de Pessoal de Nível Superior - CAPES (2014). Brasília: Ministério da Educação. Retrieved from http://www.capes.gov.br

Debert, C. G. (2003). Poder e ética na pesquisa social. Ciencia e Cultura, 5(3), 30-32.

Diniz, D., Guilhem, D. B., \& Garrafa, V. (1999). Bioethics in Brazil. Bioethics, 13(3-4), $244-248$. http://dx.doi.org/10.1111/1467-8519.00152

Diniz, D., Sugai, A., Guilhem, D., \& Squinca, F. (2008). Ética em pesquisa - temas globais. Coleção ética em pesquisa, 4. Brasília, DF, Brazil: Editora da UNB.

Freitas, C. B. D., \& Novaes, H. M. D. (2010). Lideranças de comitês de ética em pesquisa no Brasil: perfil e atuação. Bioética, 18(1), 185-200.

Gilbert, C., Fulford, K. W. M., \& Parker, C. (1989). Diversity in the practice of district ethics committees. British Medical Journal, 299(6713), 1437-1439. http://dx.doi.org/10.1136/bmj.299.6713.1437

Gold, J. L., \& Dewa, C. S. (2005). Institutional Review Boards and Multisite Studies in Health Services Research: is there a better way? Health Services Research, 40(1), 291-308. http://dx.doi.org/10.1111/j.1475-6773.2005.00354.x

Hanney, S. R., \& González-Block, M. A. (2013). Organising health research systems as a key to improving health: the World Health Report 2013 and how to make further progress. Health Research Policy and Systems, 11, 47. http://dx.doi.org/10.1186/1478-4505-11-47

Harrell, E. (2010). Doctor in MMR-Autism Scare Ruled Unethical. http://www.time.com/time/health/article/0,8599,1957656,00.html

Hossne, W. S. (2006). Bioética: princípios ou referenciais. Mundo da Saúde, 30(4), 673-676.

Instituto Brasileiro de Geografia e Estatística - IBGE (2013). Brasília: Ministério do Planejamento, Orçamento e Gestão. População: Indicadores sociais. Retrieved from http://www.ibge.gov.br/home/mapa_site/mapa_site.php\#populacao

Jacobsen, K. H. (2011). Research Ethics: principles, practices, and reporting. World Medical \& Health Policy, $3(2), 1-7$. http://onlinelibrary.wiley.com/doi/10.2202/1948-4682.1161/pdf. http://dx.doi.org/10.2202/1948-4682.1161 
Keeland, K. (2011). Medical journals retract "unethical" research. http://www.reuters.com/article/2011/03/04/us-journals-retractions-idUSTRE7235J820110304

King, N. M. P., Henderson, G. E., \& Stein, J. (1999). Beyond regulations: ethics in human subjects research. 1st edition. North Carolina, USA: The University of North Carolina Press.

Kipper, D., Loch, J. A., \& Ferrari, N. M. (1998). A experiência do comitê de ética em pesquisa da Pontifícia Universidade Católica do Rio Grande do Sul, do Comitê de Bioética do Hospital São Lucas e da Faculdade de Medicina da PUCRS. Bioética, 6(2), 203-209.

London, A. J. (2000). The ambiguity and the exigency: Clarifying "Standard of care" arguments in international $\begin{array}{llll}\text { research. Journal of Medicine and } & \text { Philosophy, 25(4), }\end{array}$ http://dx.doi.org/10.1076/0360-5310(200008)25:4;1-A;FT379

Marques, J. M. (2007). Ética em pesquisa: dez anos da Resolução CNS 196/96. Revista Brasileira de Reumatologia, 47(1), 2-3. http://dx.doi.org/10.1590/S0482-50042007000100002

Novaes, M. R. C. G., Gilhem, D., \& Lolas, F. (2008). Dez anos de experiência do Comitê de Ética em Pesquisa da Secretaria de Saúde do Distrito Federal, Brasil. Acta Bioethica, 14(2), 185-192. http://dx.doi.org/10.4067/S1726-569X2008000200008

Nunes, E. D. (2008). Ethical aspects considered by researchers who use qualitative approaches in health. Revista Ciencia \& Saude Coletiva, 13(2), 351-360. http://dx.doi.org/10.1590/S1413-81232008000200010

Oguz, N. Y. (2003). Research ethics committees in developing countries and informed consent; with special reference to Turkey. Journal of Laboratory and Clinical Medicine, 141(5), 292-296. http://dx.doi.org/10.1016/S0022-2143(03)00037-4

Ramos, F. R. S., Finkler, M., Gonçalves, E. R., \& Caetano, J. C (2010). A eticidade na pesquisa qualitativa em saúde: o dito e o não dito nas produções científicas. Revista Ciencia \& Saude Coletiva, 15, 1673-1684. http://dx.doi.org/10.1590/S1413-81232010000700079

Sarlet, I. W. (2009). Dimensões da dignidade. Ensaios de filosofia do direito e direito constitucional. 2nd edition. Porto Alegre, RS, Brazil: Livraria do Advogado.

Sawaia, B. B (2005). Limites do julgamento ético nos estudos que se valem de técnicas qualitativas. Boletim do Instituto de Saúde, 35, 22-23.

Schramm, F. R (2004). A moralidade da prática de pesquisa nas ciências sociais: aspectos epistemológicos e bioéticos. Revista Ciencia \& Saude Coletiva, 9(3), 773-784. http://dx.doi.org/10.1590/S1413-81232004000300028

Tannahill, A., \& Douglas, M. J. (2014). Ethics-based decision-making and health impact assessment. Health Promotion International, 29(1), 98-108. http://dx.doi.org/10.1093/heapro/das040

Valdez-Martinez, E., Trumbull, B., Garduño-Espinosa, J., \& Porter, J. D. H. (2005). Understanding the structure and practices of research ethics committees through research and audit: a study from Mexico. Health Policy, 74(1), 56-68. http://dx.doi.org/10.1016/j.healthpol.2004.12.014

World Health Organization (2013). The World Health Report 2013: research for universal health coverage. Retrieved from http://apps.who.int/iris/bitstream/10665/85761/2/9789240690837_eng.pdf?ua=1

\section{(cc) $\mathrm{BY}$}

This work is licensed under a Creative Commons Attribution 3.0 License. 